\title{
Cardiovascular risk associated with co-morbid insomnia and sleep apnoea (COMISA) in type 2 diabetics
}

Matthieu Hein* Jean-Pol Lanquart Anais Mungo

Gwenolé Loas

Erasme Hospital, Department of Psychiatry and Sleep Laboratory, Université libre de Bruxelles, ULB - Anderlecht - Bruxelles Belgium.
*Corresponding author:

Matthieu Hein

E-mail: matthieu.hein@erasme.ulb.ac.be / SecMed.Psy@erasme.ulb.ac.be

Received: June 24, 2021;

Accepted: September 24, 2021.

DOI: 10.5935/1984-0063.20220018

\begin{abstract}
Objective: In the general population, co-morbid insomnia and sleep apnoea (COMISA) is associated with higher risk of cardiovascular diseases (CVD). However, despite a high prevalence of COMISA in type 2 diabetics, no study has investigated its potential implication in the negative cardiovascular outcome of this particular subpopulation. The aim of this study was therefore to examine the risk of CVD associated with COMISA in type 2 diabetics.

Methods: Data from 471 type 2 diabetics recruited from the clinical database of the Erasme Hospital sleep laboratory were analysed. Only type 2 diabetics with SCORE index $\geq 5 \%$ were included in the group at high risk of CVD. Logistic regression analyses were conducted to examine the risk of CVD associated with COMISA in type 2 diabetics.

Results: A high risk of CVD was present in $32.9 \%$ of type 2 diabetics. After adjustment for the main confounding factors associated with cardiovascular risk, multivariate logistic regression analysis revealed that unlike obstructive sleep apnoea syndrome or insomnia alone, only COMISA was associated with higher risk of CVD in type 2 diabetics.

Discussion: In our study, we have demonstrated that unlike its components alone, only COMISA was associated with higher risk of CVD in type 2 diabetics, which highlights the importance of the central role played by the negative synergistic effect of COMISA on the cardiovascular outcome in this particular subpopulation. Thus, given these elements, more systematic research and adequate therapeutic management of COMISA seem to be necessary to allow better cardiovascular prevention in type 2 diabetics.
\end{abstract}

Keywords: Sleep Apnea; Obstructive; Cardiovascular Diseases; Sleep Initiation and Maintenance Disorders; Diabetes Mellitus; Type 2; Polysomnography. 


\section{INTRODUCTION}

In the literature, there are several arguments for a special relationship between type 2 diabetes and obstructive sleep apnoea syndrome (OSAS). Indeed, the prevalence of type 2 diabetes is estimated at $30.1 \%$ in apnoeic individuals and that of OSAS may reach $54.5 \%$ in type 2 diabetics. ${ }^{1,2}$ In addition, type 2 diabetes is associated with a more frequent occurrence of OSAS whereas OSAS is a risk factor for the development of type 2 diabetes., ${ }^{3,4}$ Furthermore, the co-occurrence of OSAS in type 2 diabetes is a major public health problem since it is associated with higher cardiovascular morbidity and mortality. ${ }^{5,6}$ However, despite this major role played by OSAS in the risk of cardiovascular diseases (CVD) in type 2 diabetics, it has been shown that OSAS treatments had a limited impact on glycaemia control and cardiovascular risk factors in this particular subpopulation ${ }^{7,8}$ which seems to justify carrying out additional investigations to identify the potential cofactors involved in this particular relationship between OSAS and risk of CVD in type 2 diabetics.

In the general population, comorbid complaints of insomnia appear to play a major role in the particular relationship between OSAS and risk of CVD. Indeed, compared to OSAS alone, COMISA (co-morbid insomnia and sleep apnoea) is associated with more severe cardiovascular morbidity and mortality, ${ }^{9,11}$ that may be explained by the existence of synergistic physiopathological mechanisms (deregulation of the hypothalamic-pituitary-adrenal axis, hyperactivation of the sympathetic nervous system and activation of proinflammatory mechanisms) between insomnia and OSAS. ${ }^{12}$ However, despite the significant prevalence of COMISA in type 2 diabetics, ${ }^{13}$ studies currently available in the literature have not investigated this potential negative synergic effect of COMISA on the risk of CVD in this particular subpopulation since they were limited to studying separately the cardiovascular impact of insomnia and OSAS. ${ }^{14,15}$ In addition, in studies assessing the cardiovascular impact of OSAS treatments in type 2 diabetics, ${ }^{7,16,17}$ the persistence of residual physiopathological mechanisms secondary to the lack to take into account this potential synergy between insomnia and OSAS could partially explain the limited effect of continuous positive airway pressure therapy on the risk of CVD in this subpopulation particular. Thus, in order to demonstrate this potential negative synergistic effect of COMISA on the risk of CVD in type 2 diabetics, it could be interesting to study the impact of COMISA on the cardiovascular outcome in this particular subpopulation.

Given the absence of reliable data available in the literature for healthcare professionals, the aim of our study was therefore to empirically investigate the potential negative synergic effect of COMISA on the risk of CVD in type 2 diabetics to allow the establishment of more effective cardiovascular prevention strategies in this particular subpopulation.

\section{MATERIAL AND METHODS}

\section{Population}

Based on the inclusion and exclusion criteria of this study, we recruited from the clinical database of the Erasme
Hospital sleep laboratory 471 type 2 diabetics (354 men and 117 women) who performed a usual polysomnographic examination between January 01, 2002 and December 31, 2014. Only type 2 diabetics meeting our inclusion and exclusion criteria were therefore selected from the clinical database of the Erasme Hospital sleep laboratory to constitute the sample of type 2 diabetics included in this study.

These type 2 diabetics were referred to the sleep laboratory by physicians specialised in sleep medicine after an outpatient consultation during which a preliminary assessment of their complaints related to sleep, their ongoing psychotropic/ somatic treatments and their somatic/psychiatric comorbidities was systematically carried out in order to allow a first diagnostic hypothesis. These polysomnographic examinations were performed in these type 2 diabetics to allow an objective assessment of their sleep complaints and exclude the presence of potential sleep disorders negatively impacting glycaemia control.

The inclusion criteria were age $\geq 40$ years and the presence of type 2 diabetes meeting the diagnostic criteria of the American Diabetes Association. ${ }^{18}$ The exclusion criteria were the presence of diabetes other than type 2 diabetes (type 1 diabetes, gestational diabetes, latent autoimmune diabetes, maturity diabetes onset diabetes of the young, and secondary or iatrogenic diabetes), severe uncontrolled psychiatric pathology (psychotic or bipolar disorder), heavy uncontrolled somatic pathology (chronic hepatic pathology, chronic pancreatic pathology, severe cardiovascular pathology, chronic pulmonary pathology, severe renal pathology, autoimmune pathology and pathology altering the activity of the hypothalamic-pituitary-adrenal axis such as Cushing's syndrome), infectious or inflammatory pathology, ongoing pregnancy, central hypersomnia (narcolepsy or primary hypersomnia), parasomnia, predominantly central sleep apnoea syndrome, OSAS being treated before the sleep laboratory, current or past cranial trauma, current or past central nervous system lesions involving the respiratory centres, craniofacial or thoracic cavity malformations and current or past substance abuse.

\section{Method}

Medical and psychiatric assessment of participants

Upon admission to the Erasme Hospital sleep laboratory, all individuals benefited from a review of their medical records and a complete somatic examination including blood test, electrocardiogram, day electroencephalogram, urinalysis and chest $\mathrm{x}$-ray (only for subjects over 45 years old). These different steps allow a systematic diagnosis of potential somatic pathologies in individuals admitted to our unit.

Following this complete somatic assessment, type 2 diabetes was defined as present:

When one or more of the following criteria were fulfilled at admission: glycated haemoglobin (HbA1c) $\geq 6.5 \%$ or fasting plasma glucose $\geq 126 \mathrm{mg} / \mathrm{dl}$ or two-hour plasma glucose $\geq 200 \mathrm{mg} / \mathrm{dl}$ during an oral glucose tolerance test or random plasma glucose $\geq 200 \mathrm{mg} / \mathrm{dl}$ in patients with classic symptoms 
of hyperglycaemia or hyperglycaemic crisis. In the absence of unequivocal hyperglycaemia, criteria 1-3 should be confirmed by repeat testing. In addition, diabetes must have begun in adulthood. ${ }^{18}$

Or when the patient at admission reported a biologically documented diagnosis of type 2 diabetes previously established by an outpatient diabetologist according to the diagnostic criteria of the American Diabetes Association. ${ }^{18}$

In addition, based on these criteria from the American Diabetes Association, type 2 diabetes was considered to be uncontrolled in case of glycated haemoglobin (HbA1c) $\geq 7.0 \%$ upon admission to the sleep laboratory or in case of diagnosis previously established by an outpatient diabetologist. ${ }^{19}$

Regarding the other cardiovascular risk factors, they were considered to be present on the basis of the following criteria:

Hypertension (diagnostic criteria of the World Health Organization): presence of mean systolic blood pressure $\geq 140$ $\mathrm{mmHg}$ and/or mean diastolic blood pressure $\geq 90 \mathrm{mmHg}$ or presence of self-reported diagnosis of hypertension previously established by an outpatient cardiologist or use of antihypertensive medication. ${ }^{20}$ In treated hypertensive individuals, controlled hypertension was defined as the presence of mean systolic blood pressure $<140 \mathrm{mmHg}$ and mean diastolic blood pressure $<90 \mathrm{mmHg}$ whereas uncontrolled hypertension was defined as the presence of mean systolic blood pressure $\geq 140 \mathrm{mmHg}$ and/or mean diastolic blood pressure $\geq 90$ mmHg. ${ }^{20}$

Dyslipidaemia (diagnostic criteria of the International Diabetes Federation): plasma triglyceride level $\geq 150 \mathrm{mg} / \mathrm{dl}$ or plasma HDL-cholesterol level $<40 \mathrm{mg} / \mathrm{dl}$ for men or plasma HDL-cholesterol level $<50 \mathrm{mg} / \mathrm{dl}$ for women or use of treatment for dyslipidaemia. ${ }^{21}$

Cardiovascular comorbidities (excluding hypertension): presence of one or more comorbid cardiovascular pathologies (cerebral vascular pathology, cardiac arrhythmias, coronary disease, heart disease, cardiac valve disease, peripheral vascular pathology and history of cardiac surgery).

Based on these different elements collected during this systematic somatic assessment, the SCORE index was calculated to determine the risk of CVD in type 2 diabetics included for this study. The SCORE index is used to estimate the risk of 10 -year fatal cardiovascular event related to arteriosclerosis in individuals with age $\geq 40$ years. ${ }^{22,23}$ The prediction model of the SCORE index integrates five risk factors: age, sex, smoking status, systolic blood pressure and total cholesterol. ${ }^{22,23}$ Since diabetics were automatically considered as a subpopulation requiring intensive cardiovascular prevention during the development of the SCORE index, diabetes was not initially included in the risk factors used to calculate this index. ${ }^{22,23}$ However, the SCORE index may be used in diabetic populations after some adaptations: multiplication of SCORE index obtained by 4 for women and by 2 for men suffering from diabetes. ${ }^{22,23}$ Thus, after these recommended adaptations of SCORE index, ${ }^{22,23}$ the type 2 diabetics included in this study were considered to be at low risk of CVD in case of SCORE index $<5 \%$ and at high risk of CVD in case of SCORE index $\geq 5 \%$.

Then, after this somatic assessment, a complete psychiatric interview is systematically performed by a psychiatrist from our unit in all individuals admitted to the sleep laboratory in order to diagnose potential psychiatric pathologies according to the diagnostic criteria of the DSM-IV-TR. ${ }^{24}$ Thus, following this systematic psychiatric interview, the status (current or remitted) of potential major depressive episodes was determined according to the diagnostic criteria of the DSM-IV-TR. ${ }^{24}$

Finally, during their admission to the sleep laboratory, all these individuals completed a series of self-questionnaires to assess the severity of their subjective complaints of depression (BDI 13 items), ${ }^{25}$ daytime sleepiness (Epworth Sleepiness Scale $\left[\right.$ ESS] ${ }^{26}$ and insomnia (Insomnia Severity Index [ISI]) ${ }^{27}$ (detailed description in previous study). ${ }^{28}$

Sleep evaluation and study

Upon admission to the sleep laboratory, all individuals benefited from a specific sleep interview to allow a complete assessment of their sleep-related complaints including sleeping habits, severity of self-reported insomnia complaints (difficulty falling asleep, repeated night-time awakenings, early morning awakening, and non-restorative sleep), symptoms of OSAS (snoring and self-reported apnoeas), symptoms of restless leg syndrome (RLS) (impatience of legs with or without abnormal sensations: aggravated by rest, partially or temporarily relieved by movements and increased during evening or night) and abnormal nocturnal movements (such as periodic limb movements during sleep [PLMs]).

Participants stayed in a sleep laboratory for two nights, including a first night of habituation and a second night of polysomnography from which the data were collected for analysis. The patients went to bed between 22:00 - 24:00 and got up between 6:00 - 8:00, following their usual schedule. During bedtime hours, the subjects were recumbent and the lights were turned off. Daytime naps were not permitted.

The polysomnographic recordings performed in our unit meet the recommendations of the American Academy of Sleep Medicine. ${ }^{29}$ The applied polysomnography-montage was as follows: two electro-oculogram channels, three electroencephalogram channels $(\mathrm{Fz}-\mathrm{Ax}, \mathrm{Cz}-\mathrm{Ax}$ and $\mathrm{Oz}-\mathrm{Ax}$, where Ax was a A1A2 mastoid reference), one submental electromyogram channel, electrocardiogram, thermistors to detect the oro-nasal airflow, finger pulse-oximetry, a microphone to record breathing sounds and snoring, piezoelectric sensors to measure thoracic and abdominal breathing, and anterior tibialis electrodes. EEG montage $(\mathrm{Fz}-\mathrm{Ax}, \mathrm{Cz}-\mathrm{Ax}$ and $\mathrm{Oz}-$ $\mathrm{Ax})$ is a variant of EEG montage recommended by American Academy of Sleep Medicine (F4-A1, C4-A1 and O2-A1) that is used specifically in our sleep laboratory for clinical and scientific activity. ${ }^{30,31}$ Polysomnographic recordings were visually scored by specialised technicians according to the criteria of American Academy of Sleep Medicine. ${ }^{32}$ 
Obstructive apnoeas were scored if the decrease in air flow was $\geq 90 \%$ for at least 10 seconds whereas obstructive hypopnoeas were scored if the decrease in airflow was $\geq 30 \%$ for at least 10 seconds with a decrease in oxygen saturation of $3 \%$ or followed by microarousal. ${ }^{33}$ The obstructive apnoeahypopnoea index correspond to the total number of obstructive apnoeas and hypopnoeas divided by the period of sleep in hours. OSAS was considered to be present when the obstructive apnoea-hypopnoea index was $\geq 15 /$ hour. $^{34}$

PMLs were scored on the basis of the following strict criteria: 1) duration between 0.5 to 10 seconds, 2) interval between 5 and 90 seconds from leg movement onset and 3) movements had to be part of a series of $\geq 4$ consecutive movements meeting these criteria. ${ }^{35}$ PLMs index corresponds to the total number of PLMs divided by period of sleep in hours. Moderate to severe PLMs were considered to be present when the PLMs index was $\geq 26 /$ hour. ${ }^{36}$ Moreover, the diagnoses of RLS were made according to the diagnostic criteria of the International Restless Legs Syndrome Study Group. ${ }^{37}$

The diagnoses of insomnia disorder were performed according to the diagnostic criteria of the American Academy of Sleep Medicine Work Group ${ }^{38}$ whereas sleep deprivation was defined as sleep duration $<6$ hours. ${ }^{39}$

Thus, based on these different criteria, COMISA was considered to be present in case of co-occurrence between OSAS (obstructive apnoea-hypopnoea index $\geq 15 /$ hour) and insomnia disorder.

\section{Statistical analyses}

Statistical analyses were performed using Stata 14. The normal distribution of the data was verified using histograms, boxplots, and quantile-quantile plots, and the equality of variances was checked using the Levene's test.

In order to allow our analyses, we divided our sample of type 2 diabetics into a control group at low risk of CVD and a patient group at high risk of CVD. Only type 2 diabetics with SCORE index $\geq 5 \%$ were included in the patient group at high risk of CVD.

Since most continuous data followed an asymmetric distribution, we decided to use non-parametric tests for all these variables (Wilcoxon test) in order to highlight significant differences between the medians (P25-P75) observed in the different groups of type 2 diabetics. Finally, the categorical data were described by percentage and were analysed with $\mathrm{Chi}^{2}$ tests.

Univariate logistic regression models were used to study the risk of CVD associated with COMISA disorders (categorised: absent, sleep deprivation alone, insomnia alone, OSAS alone, COMISA) and the potential confounding factors (detailed description and references available in the Supplementary Data). In multivariate logistic regression models, the risk of CVD associated with COMISA disorders was only adjusted for significant confounding factors during univariate analysis. These different confounding factors were introduced hierarchically in the different multivariate logistic regression models.
The adequacy of the final model was verified by the Hosmer and Lemeshow test whereas the specificity of the model was verified by the Link test.

The results were considered significant when the $\mathrm{p}$-value was $<0.05$.

\section{RESULTS}

Compared to those with a low risk of CVD, type 2 diabetics with a high risk of CVD showed a reduction in sleep efficiency, total sleep time, \% stage 2, \% slow-wave sleep and $\%$ REM sleep as well as an increase in \% wake after sleep onset, number of awakenings, micro-arousal index, obstructive apnoea-hypopnoea index, oxygen desaturation index, total time under $90 \%$ of Sao2 and PLMs index (Table 1). There were no significant differences between the two groups for sleep latency, sleep period time, \% stage 1 and REM latency (Table 1).

A high risk of CVD was present in $32.9 \%(n=155)$ of type 2 diabetics from our sample (Table 2). Aspirin therapy, antidiabetic therapy, overweight, obesity, alcohol consumption, dyslipidaemia status, hypertension status, cardiovascular comorbidities, depression status, sleep movement disorders and COMISA disorders were significantly associated with a high risk of CVD in type 2 diabetics (Table 2). In addition, type 2 diabetics with a high risk of CVD had higher age and lower BDI score than those with a low risk of CVD (Table 2). There were no significant differences between the two groups for gender, diabetes status, benzodiazepine receptor agonists, antidepressant therapy, caffeine consumption, smoking, snoring, ESS score, ISI score and CRP levels (Table 2). Finally, in type 2 diabetics with OSAS, COMISA was very frequent since the prevalence of comorbid insomnia disorders was $41.1 \%$ in this particular subpopulation (Table 2).

COMISA, age $\geq 55$ years, body mass index $\geq 25 \mathrm{~kg} / \mathrm{m}^{2} \&$ $<30 \mathrm{~kg} / \mathrm{m}^{2}$, body mass index $\geq 30 \mathrm{~kg} / \mathrm{m}^{2}$, aspirin therapy, absence of antidiabetic therapy, use of oral hypoglycaemic medications, alcohol consumption, dyslipidaemia with statin therapy, untreated hypertension, controlled hypertension, uncontrolled hypertension, cardiovascular comorbidities, absence of depression and RLS alone or combined with moderate to severe PLMs were significantly associated with a high risk of CVD in our population of type 2 diabetics (Table 3 ).

After adjustment for the main confounding factors associated with cardiovascular risk in the different models studied, multivariate logistic regression analysis revealed that unlike OSAS or insomnia alone, only COMISA was associated with higher risk of CVD in type 2 diabetics (Table 4).

\section{DISCUSSION}

In this study, we found that $32.9 \%$ of type 2 diabetics had a high risk of CVD. In addition, we have shown that unlike OSAS or insomnia alone, only COMISA was associated with higher risk of CVD in type 2 diabetics, which highlights the major role played by COMISA in cardiovascular risk for this particular subpopulation. 
Table 1. Polysomnographic data $(\mathrm{n}=471)$.

\begin{tabular}{|c|c|c|c|c|}
\hline & Whole Sample $(n=471)$ & $\begin{array}{c}\text { Subjects with } \\
\text { low cardiovascular risk }(n=316)\end{array}$ & $\begin{array}{c}\text { Subjects with } \\
\text { high cardiovascular risk }(n=155)\end{array}$ & P-value \\
\hline SE $(\%)$ & $76.1(66.9-83.9)$ & $79.3(70.6-86.0)$ & $71.0(62.8-79.0)$ & $<0.001$ \\
\hline TST (min) & $368.0(322.0-411.5)$ & $378.5(330.8-422.5)$ & $350.7(300.5-389.0)$ & $<0.001$ \\
\hline$\%$ stage 1 & $8.4(5.4-11.8)$ & $8.2(5.4-11.0)$ & $8.7(5.5-13.4)$ & 0.095 \\
\hline$\%$ REM sleep & $15.2(10.5-19.2)$ & $15.9(11.3-19.8)$ & $13.9(8.3-17.6)$ & $<0.001$ \\
\hline REM latency (min) & $85.7(58.7-143.0)$ & $84.0(59.5-130.5)$ & $91.5(57.3-152.7)$ & 0.258 \\
\hline$\%$ WASO & $15.2(8.6-23.9)$ & $12.2(7.4-21.3)$ & $19.5(14.1-29.4)$ & $<0.001$ \\
\hline Number of awakenings & $36(24-54)$ & $34(22-51)$ & $42(29-64)$ & $<0.001$ \\
\hline Micro-arousal index & $10(6-21)$ & $9(6-18)$ & $12(6-24)$ & 0.046 \\
\hline \multirow[t]{2}{*}{ PLMs index } & $24.4(10.4-50.1)$ & $23.6(9.7-40.7)$ & $30.6(12.3-58.3)$ & 0.018 \\
\hline & Median (P25-P75) & Median (P25-P75) & Median (P25-P75) & Wilcoxon test \\
\hline
\end{tabular}

$\mathrm{AHI}=$ apnoea-hypopnoea index, $\mathrm{ODI}=$ oxygen desaturation index, $\mathrm{PLMs}=$ periodic limb movements during sleep, REM $=$ rapid eye movement, Sao2 $=$ oxygen saturation, $\mathrm{SE}$ = sleep efficiency, $\mathrm{SL}=$ sleep latency, $\mathrm{SPT}=$ sleep period time, SWS = slow-wave sleep, TST = total sleep time, WASO = wake after sleep onset.

Table 2. Sample description $(\mathrm{n}=471)$.

\begin{tabular}{|c|c|c|c|c|c|}
\hline Variables & Categories & $\%$ & $\begin{array}{l}\text { Subjects with low } \\
\text { cardiovascular risk }\end{array}$ & $\begin{array}{l}\text { Subjects with high } \\
\text { cardiovascular risk }\end{array}$ & $\mathrm{P}$-value $\mathrm{Chi}^{2}$ \\
\hline \multirow[t]{2}{*}{ Gender } & Female $(\mathrm{n}=117)$ & $24.8 \%$ & $26.3 \%$ & $21.9 \%$ & 0.307 \\
\hline & Male $(\mathrm{n}=354)$ & $75.2 \%$ & $73.7 \%$ & $78.1 \%$ & \\
\hline \multirow[t]{2}{*}{ Aspirin therapy } & No $(n=357)$ & $75.8 \%$ & $80.4 \%$ & $66.5 \%$ & 0.001 \\
\hline & Yes $(n=114)$ & $24.2 \%$ & $19.6 \%$ & $33.5 \%$ & \\
\hline \multirow[t]{4}{*}{ Antidiabetic therapy } & Lifestyle changes $(n=159)$ & $33.7 \%$ & $38.3 \%$ & $24.5 \%$ & 0.027 \\
\hline & Untreated $(\mathrm{n}=147)$ & $31.2 \%$ & $28.5 \%$ & $36.8 \%$ & \\
\hline & Oral medications $(\mathrm{n}=118)$ & $25.1 \%$ & $23.4 \%$ & $28.4 \%$ & \\
\hline & Insulin therapy $(\mathrm{n}=47)$ & $10.0 \%$ & $9.8 \%$ & $10.3 \%$ & \\
\hline \multirow[t]{2}{*}{ Diabetes status } & Controlled $(\mathrm{n}=289)$ & $61.4 \%$ & $68.2 \%$ & $65.4 \%$ & 0.532 \\
\hline & Uncontrolled ( $\mathrm{n}=182)$ & $38.6 \%$ & $31.8 \%$ & $34.6 \%$ & \\
\hline Benzodiazepine & No $(\mathrm{n}=373)$ & $79.2 \%$ & $78.8 \%$ & $80.0 \%$ & 0.763 \\
\hline receptor agonists & Yes $(n=98)$ & $20.8 \%$ & $21.2 \%$ & $20.0 \%$ & \\
\hline Antidepressant & No $(n=351)$ & $74.5 \%$ & $75.0 \%$ & $73.5 \%$ & 0.734 \\
\hline therapy & Yes $(n=120)$ & $25.5 \%$ & $25.0 \%$ & $26.5 \%$ & \\
\hline \multirow[t]{2}{*}{ Caffeine } & No $(n=93)$ & $19.7 \%$ & $18.7 \%$ & $21.9 \%$ & 0.403 \\
\hline & Yes $(n=378)$ & $80.3 \%$ & $81.3 \%$ & $78.1 \%$ & \\
\hline \multirow[t]{2}{*}{ Smoking } & No $(n=382)$ & $81.1 \%$ & $82.0 \%$ & $79.4 \%$ & 0.497 \\
\hline & Yes $(\mathrm{n}=89)$ & $18.9 \%$ & $18.0 \%$ & $20.6 \%$ & \\
\hline \multirow[t]{2}{*}{ Alcohol } & No $(n=311)$ & $66.0 \%$ & $69.6 \%$ & $58.7 \%$ & 0.019 \\
\hline & Yes $(n=160)$ & $34.0 \%$ & $30.4 \%$ & $41.3 \%$ & \\
\hline \multirow[t]{3}{*}{ Dyslipidaemia } & No $(n=127)$ & $27.0 \%$ & $29.1 \%$ & $22.6 \%$ & 0.023 \\
\hline & Without statin therapy $(\mathrm{n}=175)$ & $37.1 \%$ & $39.2 \%$ & $32.9 \%$ & \\
\hline & With statin therapy $(\mathrm{n}=169)$ & $35.9 \%$ & $31.7 \%$ & $44.5 \%$ & \\
\hline \multirow[t]{3}{*}{ Hypertension } & No $(n=147)$ & $31.2 \%$ & $39.6 \%$ & $14.2 \%$ & $<0.001$ \\
\hline & Untreated $(\mathrm{n}=68)$ & $14.4 \%$ & $13.3 \%$ & $16.8 \%$ & \\
\hline & Controlled $(n=147)$ & $32.2 \%$ & $34.8 \%$ & $23.9 \%$ & \\
\hline Cardiovascular & No $(n=362)$ & $76.9 \%$ & $79.8 \%$ & $71.0 \%$ & 0.034 \\
\hline comorbidities & Yes $(n=109)$ & $23.1 \%$ & $20.2 \%$ & $29.0 \%$ & \\
\hline \multirow[t]{3}{*}{ Depression } & No $(\mathrm{n}=239)$ & $50.7 \%$ & $48.7 \%$ & $54.8 \%$ & 0.037 \\
\hline & Remitted ( $\mathrm{n}=106)$ & $22.5 \%$ & $20.9 \%$ & $25.8 \%$ & \\
\hline & Current $(n=126)$ & $26.8 \%$ & $30.4 \%$ & $19.4 \%$ & \\
\hline
\end{tabular}




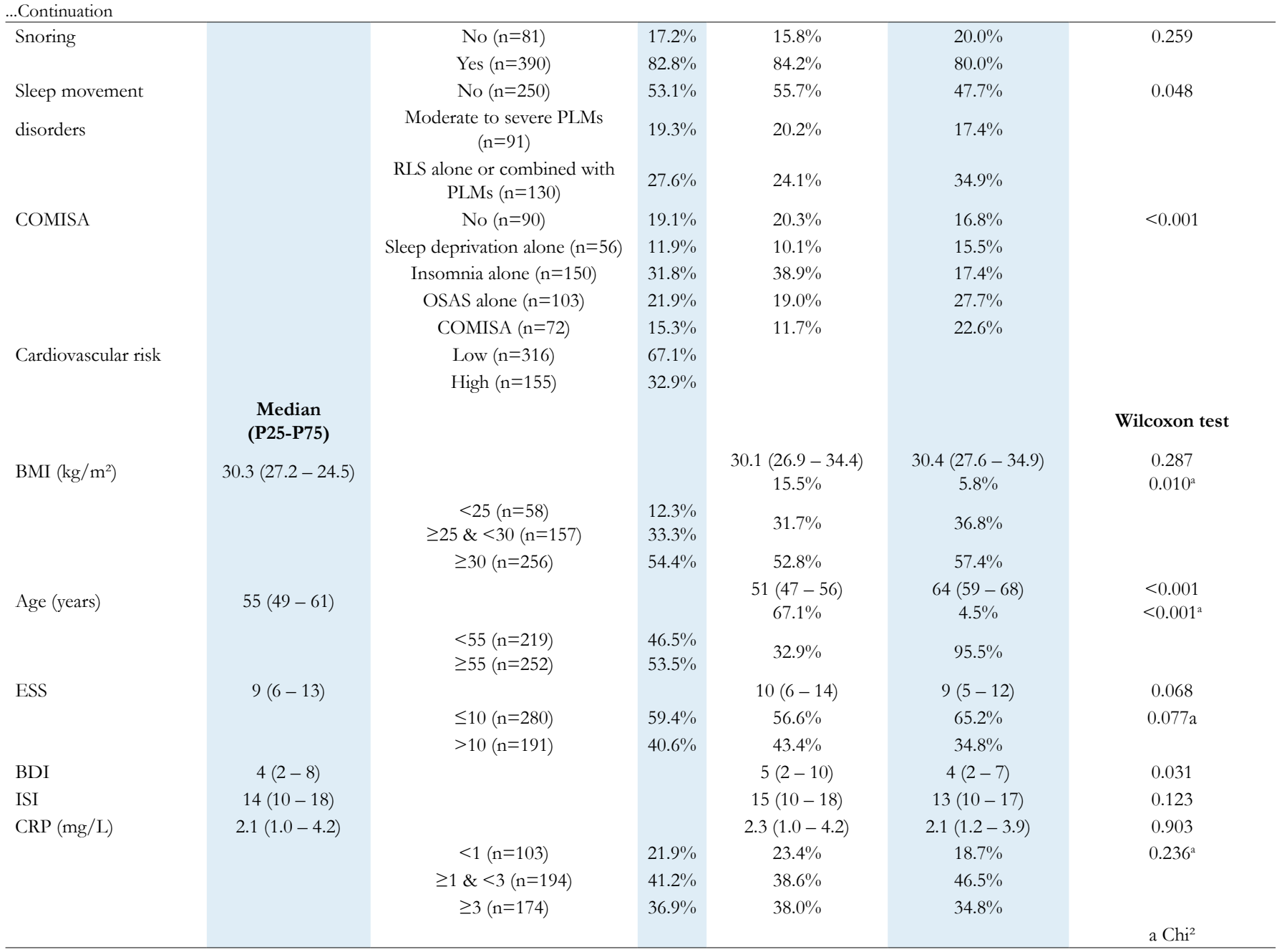

BDI = beck depression inventory, BMI = body mass index, COMISA = co-morbid insomnia and sleep apnoea, CRP = C-Reactive Protein, ESS

$=$ Epworth sleepiness scale, ISI = insomnia severity index, OSAS = obstructive sleep apnoea syndrome, PLMs $=$ periodic limb movements during sleep, RLS = restless legs syndrome.

Table 3. Univariate analysis $(\mathrm{n}=471)$.

\begin{tabular}{|c|c|c|c|c|}
\hline Variables & $\begin{array}{c}\text { Subjects } \\
\text { with low cardiovascular risk }\end{array}$ & $\begin{array}{c}\text { Subjects } \\
\text { with high cardiovascular risk }\end{array}$ & OR (CI 95\%) & P-value \\
\hline \multicolumn{5}{|l|}{ Gender } \\
\hline Female & $70.9 \%$ & $29.1 \%$ & 1 & \multirow{2}{*}{0.307} \\
\hline Male & $65.8 \%$ & $34.2 \%$ & $1.27(0.80$ to 2.00$)$ & \\
\hline \multicolumn{5}{|l|}{ Age (years) } \\
\hline$<55$ & $96.8 \%$ & $3.2 \%$ & 1 & \multirow[t]{2}{*}{$<0.001$} \\
\hline$\geq 55$ & $41.3 \%$ & $58.7 \%$ & $43.10(19.49$ to 95.31$)$ & \\
\hline \multicolumn{5}{|l|}{ BMI $\left(\mathrm{kg} / \mathrm{m}^{2}\right)$} \\
\hline$<25$ & $84.5 \%$ & $15.5 \%$ & 1 & \multirow{3}{*}{0.014} \\
\hline$\geq 25 \&<30$ & $63.7 \%$ & $36.3 \%$ & $3.10(1.42$ to 6.78$)$ & \\
\hline$\geq 30$ & $65.2 \%$ & $34.8 \%$ & $2.90(1.36$ to 6.18$)$ & \\
\hline \multicolumn{5}{|l|}{ Aspirin therapy } \\
\hline No & $71.2 \%$ & $28.8 \%$ & 1 & \multirow[t]{2}{*}{0.001} \\
\hline Yes & $54.4 \%$ & $45.6 \%$ & 2.07 (1.34 to 3.19$)$ & \\
\hline Antidiabetic therapy & & & & 0.029 \\
\hline Lifestyle changes & $76.1 \%$ & $23.9 \%$ & 1 & \\
\hline Untreated & $61.2 \%$ & $38.8 \%$ & $2.02(1.23$ to 3.30$)$ & \\
\hline Oral medications & $62.7 \%$ & $37.3 \%$ & $1.89(1.12$ to 3.19$)$ & \\
\hline Insulin therapy & $66.0 \%$ & $34.0 \%$ & $1.64(0.81$ to 3.33$)$ & \\
\hline Diabetes status & & & & 0.532 \\
\hline Controlled & $62.3 \%$ & $37.7 \%$ & 1 & \\
\hline
\end{tabular}




\begin{tabular}{|c|c|c|c|c|}
\hline Uncontrolled & $59.4 \%$ & $40.6 \%$ & 1.13 (0.77 to 1.68$)$ & \\
\hline \multicolumn{5}{|l|}{$\begin{array}{l}\text { Benzodiazepine receptor } \\
\text { agonists }\end{array}$} \\
\hline No & $66.8 \%$ & $33.2 \%$ & 1 & \multirow{2}{*}{0.763} \\
\hline Yes & $68.4 \%$ & $31.6 \%$ & 0.93 (0.58 to 1.50$)$ & \\
\hline \multicolumn{5}{|l|}{ Antidepressant therapy } \\
\hline No & $67.5 \%$ & $32.5 \%$ & 1 & \multirow[t]{2}{*}{0.734} \\
\hline Yes & $65.8 \%$ & $34.2 \%$ & $1.08(0.70$ to 1.67$)$ & \\
\hline \multicolumn{5}{|l|}{ Caffeine } \\
\hline No & $63.4 \%$ & $36.6 \%$ & 1 & \multirow{2}{*}{0.403} \\
\hline Yes & $68.0 \%$ & $32.0 \%$ & 0.82 (0.51 to 1.31$)$ & \\
\hline \multicolumn{5}{|l|}{ Smoking } \\
\hline No & $67.8 \%$ & $32.2 \%$ & 1 & \multirow{2}{*}{0.497} \\
\hline Yes & $64.0 \%$ & $36.0 \%$ & 1.18 (0.73 to 1.92$)$ & \\
\hline \multicolumn{5}{|l|}{ Alcohol } \\
\hline No & $70.7 \%$ & $29.3 \%$ & 1 & \multirow{2}{*}{0.019} \\
\hline Yes & $60.0 \%$ & $40.0 \%$ & $1.61(1.08$ to 2.40$)$ & \\
\hline \multicolumn{5}{|l|}{ Dyslipidaemia } \\
\hline No & $72.4 \%$ & $27.6 \%$ & 1 & \multirow{3}{*}{0.024} \\
\hline Without statin therapy & $70.9 \%$ & $29.1 \%$ & $1.08(0.65$ to 1.80$)$ & \\
\hline With statin therapy & $59.2 \%$ & $40.8 \%$ & $1.81(1.10$ to 2.98$)$ & \\
\hline \multicolumn{5}{|l|}{ Hypertension } \\
\hline No & $85.0 \%$ & $15.0 \%$ & 1 & \multirow{4}{*}{$<0.001$} \\
\hline Untreated & $61.8 \%$ & $38.2 \%$ & $3.52(1.81$ to 6.85$)$ & \\
\hline Controlled & $74.8 \%$ & $25.2 \%$ & 1.91 (1.06 to 3.44$)$ & \\
\hline Uncontrolled & $35.8 \%$ & $64.2 \%$ & $10.20(5.60$ to 18.56$)$ & \\
\hline \multicolumn{5}{|l|}{$\begin{array}{l}\text { Cardiovascular } \\
\text { comorbidities }\end{array}$} \\
\hline No & $69.6 \%$ & $30.4 \%$ & 1 & \multirow{2}{*}{0.035} \\
\hline Yes & $58.7 \%$ & $41.3 \%$ & 1.61 (1.04 to 2.51$)$ & \\
\hline \multicolumn{5}{|l|}{ Depression } \\
\hline No & $64.4 \%$ & $35.6 \%$ & 1 & \multirow{3}{*}{0.039} \\
\hline Remitted & $62.3 \%$ & $37.7 \%$ & $1.10(0.68$ to 1.76$)$ & \\
\hline Current & $76.2 \%$ & $23.8 \%$ & 0.57 (0.35 to 0.92$)$ & \\
\hline \multicolumn{5}{|l|}{ Snoring } \\
\hline No & $70.4 \%$ & $29.6 \%$ & 1 & \multirow{2}{*}{0.260} \\
\hline Yes & $68.2 \%$ & $31.8 \%$ & 0.75 (0.46 to 1.23$)$ & \\
\hline \multicolumn{5}{|l|}{ Sleep movement disorders } \\
\hline No & $70.4 \%$ & $29.6 \%$ & 1 & \\
\hline Moderate to severe PLMs & $70.3 \%$ & $29.7 \%$ & $1.00(0.59$ to 1.70$)$ & 0.049 \\
\hline $\begin{array}{l}\text { RLS alone or combined } \\
\text { with PLMs }\end{array}$ & $58.5 \%$ & $41.5 \%$ & 1.69 (1.09 to 2.63$)$ & \\
\hline COMISA & & & & \\
\hline No & $71.1 \%$ & $28.9 \%$ & 1 & \\
\hline Sleep deprivation alone & $57.1 \%$ & $42.9 \%$ & $1.85(0.92$ to 3.71$)$ & \\
\hline Insomnia alone & $82.0 \%$ & $18.0 \%$ & $0.54(0.29$ to 1.01$)$ & $<0.001$ \\
\hline OSAS alone & $58.2 \%$ & $41.8 \%$ & $1.76(0.97$ to 3.22$)$ & \\
\hline COMISA & $51.4 \%$ & $48.6 \%$ & 2.33 (1.22 to 4.46$)$ & \\
\hline $\mathrm{CRP}(\mathrm{mg} / \mathrm{L})$ & & & & \\
\hline$<1$ & $71.8 \%$ & $28.2 \%$ & 1 & \\
\hline$\geq 1 \&<3$ & $62.9 \%$ & $37.1 \%$ & 1.51 (0.90 to 2.53$)$ & 0.238 \\
\hline$\geq 3$ & $69.0 \%$ & $31.0 \%$ & 1.15 (0.67 to 1.96$)$ & \\
\hline ESS & & & & \\
\hline$\leq 10$ & $63.9 \%$ & $36.1 \%$ & 1 & 0.078 \\
\hline$>10$ & $71.7 \%$ & $28.3 \%$ & 0.70 (0.47 to 1.04$)$ & 0.010 \\
\hline
\end{tabular}

BMI $=$ body mass index, COMISA $=$ co-morbid insomnia and sleep apnoea, CRP $=$ C-Reactive Protein, ESS $=$ Epworth sleepiness scale, OSAS $=$ obstructive sleep apnoea syndrome, RLS = restless legs syndrome, PLMs = periodic limb movements during sleep. 
Table 4. Multivariate analysis $(\mathrm{n}=471)$.

\begin{tabular}{|c|c|c|c|c|c|c|c|c|}
\hline Variables & $\begin{array}{c}\text { Model 1 OR } \\
\text { adjusted (CI 95\%) }\end{array}$ & $\begin{array}{c}\text { P- } \\
\text { value }\end{array}$ & $\begin{array}{c}\text { Model } 2 \text { OR } \\
\text { adjusted (CI 95\%) }\end{array}$ & $\begin{array}{c}\text { P- } \\
\text { value }\end{array}$ & $\begin{array}{c}\text { Model } 3 \text { OR } \\
\text { adjusted (CI 95\%) }\end{array}$ & $\begin{array}{c}P- \\
\text { value }\end{array}$ & $\begin{array}{c}\text { Model } 4 \text { OR } \\
\text { adjusted (CI 95\%) }\end{array}$ & $\begin{array}{c}\text { P- } \\
\text { value }\end{array}$ \\
\hline COMISA & & $<0.001$ & & 0.001 & & 0.014 & & 0.021 \\
\hline No & 1 & & 1 & & 1 & & 1 & \\
\hline Sleep deprivation alone & 1.77 (0.87 to 3.61$)$ & & $1.73(0.79$ to 3.80$)$ & & $1.87(0.67$ to 5.20$)$ & & $1.72(0.61$ to 4.84$)$ & \\
\hline Insomnia alone & $0.56(0.30$ to 1.05$)$ & & $0.61(0.31$ to 1.21$)$ & & $0.71(0.29$ to 1.76$)$ & & 0.85 (0.33 to 2.19$)$ & \\
\hline OSAS alone & $1.68(0.91$ to 3.12$)$ & & $1.75(0.89$ to 3.44$)$ & & 1.55 (0.63 to 3.82$)$ & & $1.58(0.63$ to 3.96$)$ & \\
\hline COMISA & $2.26(1.17$ to 4.38$)$ & & $2.40(1.15$ to 5.01$)$ & & 3.41 (1.24 to 9.41$)$ & & $4.00(1.39$ to 11.48$)$ & \\
\hline
\end{tabular}

Model $1=$ Model adjusted for aspirin therapy and antidiabetic therapy.

Model 2 = Model adjusted for aspirin therapy, antidiabetic therapy, dyslipidaemia, hypertension and cardiovascular comorbidities.

Model 3 = Model adjusted for aspirin therapy, antidiabetic therapy, dyslipidaemia, hypertension, cardiovascular comorbidities, age, BMI and alcohol.

Model 4 = Model adjusted for aspirin therapy, antidiabetic therapy, dyslipidaemia, hypertension, cardiovascular comorbidities, age, BMI, alcohol, depression and sleep movement disorders. BMI = body mass index, COMISA = co-morbid insomnia and sleep apnoea, OSAS = obstructive sleep apnoea syndrome.

Following our results, we confirmed that type 2 diabetics are a subpopulation at high risk of CVD. Indeed, we have demonstrated that a high risk of 10 -year fatal cardiovascular event was present in $32.9 \%$ of type 2 diabetics from our sample. Despite some methodological differences in recruitment, our results seem similar to those of the study by Nagpal and Bhartia (2008) where as in our study, the SCORE index showed a high risk of 10 -year fatal cardiovascular event in $35.7 \%$ of type 2 diabetics. ${ }^{40}$ At the physiopathological level, the occurrence of several interrelated mechanisms (such as oxidative stress, proinflammatory mechanisms, endothelial dysfunction, recurrent hypoglycaemia, autonomic neuropathies and synergistic effect of other cardiovascular risk factors [obesity, dyslipidaemia and hypertension]) could partially explain this particular relationship between type 2 diabetes and CVD. ${ }^{41,42}$ However, although there are arguments in favour of a reduction in these physiopathological mechanisms related to this deleterious cardiovascular outcome in case of intensive management of type 2 diabetes, ${ }^{43}$ CVD remain the leading cause of mortality in type 2 diabetics. ${ }^{44}$ These elements therefore indicate the need to identify the potential comorbidities involved in this less favourable cardiovascular prognosis in type 2 diabetics to allow better cardiovascular prevention in this particular subpopulation.

Consistent with the literature, ${ }^{45,46}$ we confirmed that OSAS is a frequent comorbidity $(37.2 \%)$ in type 2 diabetics. In addition, we have shown that similar to the general population, ${ }^{47}$ comorbid complaints of insomnia are frequent in type 2 diabetics with OSAS. Indeed, in our study, comorbid complaints of insomnia were present in $41.1 \%$ of type 2 diabetics with OSAS, which highlights the importance of COMISA in this particular subpopulation. The existence of this frequent co-occurrence of OSAS and insomnia in type 2 diabetics could potentially be explained by the presence of some physiopathological mechanisms specific to this particular subpopulation favouring the concomitant development of these two sleep disorders. ${ }^{48,49,50}$ Indeed, the polyneuropathies induced by type 2 diabetes may promote the occurrence of obstructive respiratory events through alterations in central control of breathing and upper airway reflexes whereas alterations in the hypothalamic-pituitary-adrenal axis induced by complex interactions between impaired glucocorticoid negative feedback sensitivity and some factors (such as hypoinsulinemia, hyperglycaemia and/or hypoleptinemia) may promote the development of insomnia in type 2 diabetics. ${ }^{48,49,50}$ Furthermore, we have demonstrated that compared to OSAS or insomnia alone, only COMISA was associated with higher risk of CVD in type 2 diabetics, which demonstrates the importance of the central role played by the negative synergistic effect of COMISA on the cardiovascular outcome in this particular subpopulation. At the physiopathological level, similar to the general population, ${ }^{12,51}$ this central role played by the negative synergy of COMISA on cardiovascular risk in type 2 diabetics could be explained by the presence of a cumulative effect of deleterious mechanisms related to OSAS and insomnia (deregulation of the hypothalamic-pituitary-adrenal axis, hyperactivation of the sympathetic nervous system and activation of pro-inflammatory mechanisms) promoting the development of CVD. Thus, given these different elements, it seems to be necessary to systematically research for potential comorbid complaints of insomnia in type 2 diabetics with OSAS to allow the establishment of adapted therapeutic strategies and better cardiovascular outcome in this particular subpopulation.

At the therapeutic level, the highlight of this negative synergic effect of COMISA on the risk of CVD in type 2 diabetics could help better understand the limited impact of continuous positive airway pressure therapy alone on the cardiovascular risk in this particular population. ${ }^{7,16,17}$ Indeed, in type 2 diabetics with OSAS, the lack of adequate management of the potential comorbid complaints of insomnia could promote the maintenance of the pathophysiological mechanisms related to the development of $\mathrm{CVD}^{52}$ both by the direct negative impact of insomnia on the cardiovascular prognosis ${ }^{53}$ and by the indirect negative impact of insomnia on the compliance and efficacy of OSAS treatments. ${ }^{54,55}$ However, although the establishment of combined therapeutic strategies for COMISA could be a promising option to allow better cardiovascular prevention in some type 2 diabetics ${ }^{56}$ these combined treatments should take into account the specific characteristics of this particular subpopulation in order to avoid the implementation of treatments with deleterious effects on the management of diabetes. ${ }^{57}$ Indeed, given the potential negative effect of most pharmacological treatments for insomnia on glycaemia 
metabolism and the few data available on the impact of therapeutic alternatives to continuous positive airway pressure therapy on glycaemia parameters in type 2 diabetics, ${ }^{57,58,59}$ the combination of cognitive-behavioural therapies for insomnia and continuous positive airway pressure therapy associated with lifestyle changes (weight loss and sports activity) seems to be the best option for first-line treatment of COMISA in this particular subpopulation. ${ }^{57}$ Finally, regardless of this potential impact on the cardiovascular prognosis, the implementation of adequate treatments for insomnia and OSAS (even in the absence of cooccurrence) is essential given the negative impact of these two pathologies on life quality, diabetes self-care behaviours and patient-reported outcomes in type 2 diabetics. ${ }^{60}$

\section{Limitations}

The results obtained in our study come from retrospective data that, even if they have been encoded in a systematic manner, cannot be verified directly with the subject in most cases, which means that our results need to be replicated in prospective studies. Moreover, we focused only on type 2 diabetes, which means that our results cannot be generalized to other types of diabetes (such as type 1 diabetes, gestational diabetes, latent autoimmune diabetes, maturity diabetes onset diabetes of the young, and secondary or iatrogenic diabetes). Furthermore, although its use is validated in diabetic populations, the SCORE index was initially developed for the general population, which requires strict compliance with the adaptations recommended for diabetic populations in order to avoid the potential limitations related to its use in these particular subpopulations. Finally, our database only contains type 2 diabetics who have agreed to perform a sleep laboratory, which may also limit the generalisation of our results.

\section{CONCLUSIONS}

In our study, we confirmed that type 2 diabetics are a subpopulation at high cardiovascular risk. In addition, we have demonstrated that unlike its components alone, only COMISA was associated with higher risk of CVD in type 2 diabetics, which highlights the importance of the central role played by the negative synergistic effect of COMISA on the cardiovascular outcome in this particular subpopulation. Thus, given these elements, more systematic research and adequate therapeutic management of COMISA seem to be necessary to allow better cardiovascular prevention in type 2 diabetics.

\section{DECLARATIONS}

\section{Ethics approval and consent to participate}

This research protocol was approved by the Hospital and Medical School Ethics Committee of the Erasme Hospital (Brussels University Clinics) (Erasme Reference: P2021/080). At Erasme Hospital, all patients are informed that their data could be used retrospectively for scientific research. If patients do not wish for their data to be used, they must inform the hospital, at which time, this directive is indicated in their medical records, and any future use of their data is prohibited.

\section{Consent for publication}

Not applicable.

\section{Availability of data and material}

The datasets used and/or analysed during the current study are available from the corresponding author on reasonable request.

\section{Competing interests}

The authors have no conflicts of interest with the work carried out in this study.

\section{Funding}

This research did not receive any specific grant from funding agencies in the public, commercial, or not-for-profit sectors.

\section{Authors' contributions}

MH: Principal investigator of the study with active participation in the encoding of data, statistical analysis, interpretation of results and writing of the article. JL: Active participation in the extraction and calculation of data from polysomnography for the realisation of the database. AM: Support in drafting the manuscript and supervision of research work. GL: Support in drafting the manuscript and supervision of research work. All authors read and approved the final manuscript.

\section{ACKNOWLEDGEMENTS}

I want to thank Christelle Bouchart (MD) for this support as well as the sleep laboratory team from the Erasme Hospital for technical support.

\section{REFERENCES}

1. Fallahi A, Jamil DI, Karimi EB, Baghi V, Gheshlagh RG. Prevalence of obstructive sleep apnea in patients with type 2 diabetes: A systematic review and meta-analysis. Diabetes Metab Syndr. 2019;13(4):2463-2468.

2. Mahmood K, Akhter N, Eldeirawi K, Onal E, Christman JW, Carley DW, Herdegen JJ. Prevalence of type 2 diabetes in patients with obstructive sleep apnea in a multi-ethnic sample. J Clin Sleep Med. 2009;5(3):215-221.

3. Wang X, Bi Y, Zhang Q, Pan F. Obstructive sleep apnoea and the risk of type 2 diabetes: a meta-analysis of prospective cohort studies. Respirology. 2013;18(1):140-146.

4. Huang T, Lin BM, Stampfer MJ, Tworoger SS, Hu FB, Redline S. A Population-Based Study of the Bidirectional Association Between Obstructive Sleep Apnea and Type 2 Diabetes in Three Prospective U.S. Cohorts. Diabetes Care. 2018;41(10):2111-2119.

5. Adderley NJ, Subramanian A, Toulis K, Gokhale K, Taverner T, Hanif W, Haroon S, Thomas GN, Sainsbury C, Tahrani AA, Nirantharakumar K. Obstructive Sleep Apnea, a Risk Factor for Cardiovascular and Microvascular Disease in Patients With Type 2 Diabetes: Findings From a Population-Based Cohort Study. Diabetes Care. 2020;43(8):1868-1877.

6. Labarca G, Dreyse J, Salas C, Schmidt A, Rivera F, Letelier F, Jorquera J. Risk of mortality among patients with moderate to severe obstructive sleep apnea and diabetes mellitus: results from the SantOSA cohort. 
Sleep Breath. 2021. doi: 10.1007/s11325-020-02283-y.

7. Myhill PC, Davis WA, Peters KE, Chubb SA, Hillman D, Davis TM. Effect of continuous positive airway pressure therapy on cardiovascular risk factors in patients with type 2 diabetes and obstructive sleep apnea. J Clin Endocrinol Metab. 2012;97(11):4212-4218.

8. Zhu B, Ma C, Chaiard J, Shi C. Effect of continuous positive airway pressure on glucose metabolism in adults with type 2 diabetes: a systematic review and meta-analysis of randomized controlled trials. Sleep Breath. 2018;22(2):287-295.

9. Gupta MA, Knapp K. Cardiovascular and psychiatric morbidity in obstructive sleep apnea (OSA) with insomnia (sleep apnea plus) versus obstructive sleep apnea without insomnia: a case-control study from a Nationally Representative US sample. PLoS One. 2014;9(3):e90021.

10. Anttalainen U, Grote L, Fietze I, Riha RL, Ryan S, Staats R, Hedner J, Saaresranta T; ESADA Study Collaborators. Insomnia symptoms combined with nocturnal hypoxia associate with cardiovascular comorbidity in the European sleep apnea cohort (ESADA). Sleep Breath. 2019;23(3):805-814.

11. Cho YW, Kim KT, Moon HJ, Korostyshevskiy VR, Motamedi GK, Yang KI. Comorbid Insomnia With Obstructive Sleep Apnea: Clinical Characteristics and Risk Factors. J Clin Sleep Med. 2018;14(3):409-417.

12. Benetó A, Gomez-Siurana E, Rubio-Sanchez P. Comorbidity between sleep apnea and insomnia. Sleep Med Rev. 2009;13(4):287-293.

13. Hein M, Lanquart JP, Loas G, Hubain P, Linkowski P. Prevalence and risk factors of type 2 diabetes in insomnia sufferers: a study on 1311 individuals referred for sleep examinations. Sleep Med. 2018;46:37-45.

14. Seicean S, Strohl KP, Seicean A, Gibby C, Marwick TH. Sleep disordered breathing as a risk of cardiac events in subjects with diabetes mellitus and normal exercise echocardiographic findings. Am J Cardiol. 2013;111(8):1214-1220.

15. Sudore RL, Karter AJ, Huang ES, Moffet HH, Laiteerapong N, Schenker Y, Adams A, Whitmer RA, Liu JY, Miao Y, John PM, Schillinger D. Symptom burden of adults with type 2 diabetes across the disease course: diabetes $\&$ aging study. J Gen Intern Med. 2012;27(12):1674-1681.

16. Dorkova Z, Petrasova D, Molcanyiova A, Popovnakova M, Tkacova R. Effects of continuous positive airway pressure on cardiovascular risk profile in patients with severe obstructive sleep apnea and metabolic syndrome. Chest. 2008;134(4):686-692.

17. Bakker JP, Baltzis D, Tecilazich F, Chan RH, Manning WJ, Neilan TG, Wallace ML, Hudson M, Malhotra A, Patel SR, Veves A. The Effect of Continuous Positive Airway Pressure on Vascular Function and Cardiac Structure in Diabetes and Sleep Apnea. A Randomized Controlled Trial. Ann Am Thorac Soc. 2020;17(4):474-483.

18. American Diabetes Association. Diagnosis and classification of diabetes mellitus. Diabetes Care. 2014;37 Suppl 1:S81-90.

19. American Diabetes Association. Standards of Medical Care in Diabetes-2017 Abridged for Primary Care Providers. Clin Diabetes. 2017;35(1):5-26.

20. Mills KT, Bundy JD, Kelly TN, Reed JE, Kearney PM, Reynolds $\mathrm{K}$, Chen J, He J. Global disparities of hypertension prevalence and control: A systematic analysis of population-based studies from 90 countries. Circulation. 2016;134(6):441-450.

21. Alberti KG, Eckel RH, Grundy SM, Zimmet PZ, Cleeman JI, Donato KA, Fruchart JC, James WP, Loria CM, Smith SC Jr; International Diabetes Federation Task Force on Epidemiology and Prevention; Hational Heart, Lung, and Blood Institute; American Heart Association; World Heart Federation; International Atherosclerosis Society; International Association for the Study of Obesity. Harmonizing the metabolic syndrome: a joint interim statement of the International Diabetes Federation Task Force on Epidemiology and Prevention; National Heart, Lung, and Blood Institute; American Heart Association; World Heart Federation; International Atherosclerosis Society; and International Association for the Study of Obesity. Circulation. 2009;120(16):1640-1645.

22. Conroy RM, Pyörälä K, Fitzgerald AP, Sans S, Menotti A, De Backer G, De Bacquer D, Ducimetière P, Jousilahti P, Keil U, Niølstad I, Oganov RG, Thomsen T, Tunstall-Pedoe H, Tverdal A, Wedel H, Whincup P, Wilhelmsen L, Graham IM; SCORE project group. Estimation of ten-year risk of fatal cardiovascular disease in Europe: the SCORE project. Eur Heart J. 2003;24(11):987-1003.

23. van der Heijden AA, Ortegon MM, Niessen LW, Nijpels G, Dekker JM. Prediction of coronary heart disease risk in a general, pre-diabetic, and diabetic population during 10 years of follow-up: accuracy of the Framingham, SCORE, and UKPDS risk functions: The Hoorn Study. Diabetes Care. 2009;32(11):2094-2098.

24. American Psychiatric Association. Diagnostic and statistical manual of mental disorders. 4th ed., text rev: American Psychiatric Publishing, Arlington, VA;2000.

25. Beck AT, Steer RA, Ball R, Ranieri W. Comparison of Beck Depression Inventories -IA and -II in psychiatric outpatients. J Pers Assess. 1996;67(3):588-597.

26. Johns MW. A new method for measuring daytime sleepiness: the Epworth sleepiness scale. Sleep. 1991;14(6):540-545.

27. Morin CM. Insomnia: psychological assessment and management. Guilford Press, NY;1993.

28. Hein M, Lanquart JP, Mungo A, Hubain P, Loas G. Impact of number of sleep ultradian cycles on polysomnographic parameters related to REM sleep in major depression: Implications for future sleep research in psychiatry. Psychiatry Res. 2020;285:112818.

29. Kushida CA, Littner MR, Morgenthaler T, Alessi CA, Bailey D, Coleman J Jr, Friedman L, Hirshkowitz M, Kapen S, Kramer M, Lee-Chiong T, Loube DL, Owens J, Pancer JP, Wise M. Practice Parameters for the Indications for Polysomnography and Related Procedures: An Update for 2005. Sleep. 2005;28(4):499-521.

30. Hein M, Lanquart JP, Loas G, Hubain P, Linkowski P. Risk of high blood pressure associated with objective insomnia and selfreported insomnia complaints in major depression: A study on 703 individuals. Clin Exp Hypertens. 2019:41(6);538-547.

31. Hein M, Lanquart JP, Hubain P, Loas G. Risk of resistant hypertension associated with restless legs syndrome and periodic limb movements during sleep: A study on 673 treated hypertensive individuals. Sleep Med. 2019;63:46-56.

32. Iber C, Ancoli-Israel S, Chesson A, Quan SF for the American Academy of Sleep Medicine. The AASM Manual for the Scoring of Sleep and Associated Events: Rules, Terminology and Technical Specifications. 1st. ed: American Academy of Sleep Medicine, Westchester, IL;2007.

33. Berry RB, Budhiraja R, Gottlieb DJ, Gozal D, Iber C, Kapur VK, Marcus CL, Mehra R, Parthasarathy S, Quan SF, Redline S, Strohl KP, Davidson Ward SL, Tangredi MM; American Academy of Sleep Medicine. Rules for scoring respiratory events in sleep: update of the 2007 AASM Manual for the Scoring of Sleep and Associated Events. Deliberations of the Sleep Apnea Definitions Task Force of the American Academy of Sleep Medicine. J Clin Sleep Med. 2012;8(5):597-619.

34. Fleetham J, Ayas N, Bradley D, Ferguson K, Fitzpatrick M, George C, Hanly P, Hill F, Kimoff J, Kryger M, Morrison D, Series F, Tsai W; CTS Sleep Disordered Breathing Committee. Canadian Thoracic Society guidelines: diagnosis and treatment of sleep disordered breathing in adults. Can Respir J. 2006;13(7):387-392.

35. Ferri R, Koo BB, Picchietti DL, Fulda S. Periodic leg movements during sleep: phenotype, neurophysiology, and clinical significance. Sleep Med. 2017;31:29-38.

36. Aurora RN, Kristo DA, Bista SR, Rowley JA, Zak RS, Casey KR, Lamm CI, Tracy SL, Rosenberg RS. Update to the AASM clinical practice guideline: "the treatment of restless legs syndrome and periodic limb movement disorder in adults-an update for 2012: practice parameters with an evidence-based systematic review and meta-analyses." Sleep. 2012;35(8):1037.

37. Allen RP, Picchietti DL, Garcia-Borreguero D, Ondo WG, Walters AS, Winkelman JW, Zucconi M, Ferri R, Trenkwalder C, Lee HB; International Restless Legs Syndrome Study Group. Restless legs syndrome/Willis-Ekbom disease diagnostic criteria: updated International Restless Legs Syndrome Study Group (IRLSSG) consensus criteria--history, rationale, description, and significance. Sleep Med. 2014;15(8):860-873.

38. Edinger JD, Bonnet MH, Bootzin RR, Doghramji K, Dorsey CM, Espie CA, Jamieson AO, McCall WV, Morin CM, Stepanski EJ; American Academy of Sleep Medicine Work Group. Derivation of research diagnostic criteria for insomnia: report of an American Academy of Sleep Medicine Work Group. Sleep. 2004;27(8):1567-1596.

39. Hein M, Lanquart JP, Loas G, Hubain P, Linkowski P. Insomnia with short sleep duration as risk factor for type 2 diabetes: a systematic review of the literature. Rev Med Brux. 2020;41(2):98-104.

40. Nagpal J, Bhartia A. Cardiovascular risk profile of subjects 
with known diabetes from the middle- and high-income group population of Delhi: the DEDICOM survey. Diabet Med. 2008;25(1):27-36.

41. Katakami N. Mechanism of Development of Atherosclerosis and Cardiovascular Disease in Diabetes Mellitus. J Atheroscler Thromb. 2018;25(1):27-39.

42. Patel TP, Rawal K, Bagchi AK, Akolkar G, Bernardes N, Dias DDS, Gupta S, Singal PK. Insulin resistance: an additional risk factor in the pathogenesis of cardiovascular disease in type 2 diabetes. Heart Fail Rev. 2016;21(1):11-23.

43. Henning RJ. Type-2 diabetes mellitus and cardiovascular disease. Future Cardiol. 2018;14(6):491-509.

44. Laakso M, Kuusisto J. Insulin resistance and hyperglycaemia in cardiovascular disease development. Nat Rev Endocrinol. 2014;10(5):293-302.

45. Ogilvie RP, Patel SR. The Epidemiology of Sleep and Diabetes. Curr Diab Rep. 2018;18(10):82.

46. Hein M, Lanquart JP, Loas G, Hubain P, Linkowski P. Prevalence and Risk Factors of Type 2 Diabetes in Major Depression: A Study on 703 Individuals Referred for Sleep Examinations. Psychosomatics. 2018;59(2):144-157.

47. Sweetman A, Lack L, Bastien C. Co-Morbid Insomnia and Sleep Apnea (COMISA): Prevalence, Consequences, Methodological Considerations, and Recent Randomized Controlled Trials. Brain Sci. 2019;9(12):371.

48. Reutrakul S, Mokhlesi B. Obstructive Sleep Apnea and Diabetes: A State of the Art Review. Chest. 2017;152(5):1070-1086.

49. Chan O, Inouye K, Riddell MC, Vranic M, Matthews SG. Diabetes and the hypothalamo-pituitary-adrenal (HPA) axis. Minerva Endocrinol. 2003;28(2):87-102.

50. Gemignani A, Piarulli A, Menicucci D, Laurino M, Rota G, Mastorci F, Gushin V, Shevchenko O, Garbella E, Pingitore A, Sebastiani L, Bergamasco M, L'Abbate A, Allegrini P, Bedini R. How stressful are 105 days of isolation? Sleep EEG patterns and tonic cortisol in healthy volunteers simulating manned flight to Mars. Int J Psychophysiol. 2014;93(2):211-219.

51. Luyster FS, Buysse DJ, Strollo PJ Jr. Comorbid insomnia and obstructive sleep apnea: challenges for clinical practice and research. J Clin Sleep Med. 2010;6(2):196-204.

52. Javaheri S, Redline S. Insomnia and Risk of Cardiovascular Disease. Chest. 2017;152(2):435-444.

53. Khan MS, Aouad R. The Effects of Insomnia and Sleep Loss on Cardiovascular Disease. Sleep Med Clin. 2017;12(2):167-177.

54. Drakou T, Steiropoulos P, Saroglou M, Georgopoulou A, Kazis D, Papagiannopoulos S, Porpodis K, Tryfon S. The presence of insomnia and depression contributes to the acceptance of an initial treatment trial of continuous positive airway pressure therapy in patients with obstructive sleep apnea. Sleep Breath. 2021. doi: 10.1007/s11325-020-02266-z.

55. Salman LA, Shulman R, Cohen JB. Obstructive Sleep Apnea, Hypertension, and Cardiovascular Risk: Epidemiology, Pathophysiology, and Management. Curr Cardiol Rep. 2020;22(2):6.

56. Grandner MA, Alfonso-Miller P, Fernandez-Mendoza J, Shetty S, Shenoy S, Combs D. Sleep: important considerations for the prevention of cardiovascular disease. Curr Opin Cardiol. 2016;31(5):551-565.

57. Tan X, van Egmond L, Chapman CD, Cedernaes J, Benedict C. Aiding sleep in type 2 diabetes: therapeutic considerations. Lancet Diabetes Endocrinol. 2018;6(1):60-68.

58. Hein M, Hubain P, Linkowski P, Loas G. Support for insomnia: Recommendations for practice in general medicine. Rev Med Brux. 2016;37(4):235-241.

59. Gupta A, Tripathi A, Rai P, Sharma S, Yadav V, Kumar D. Effect of Mandibular Advancement Splint on Obstructive Sleep Apnea with Insulin Resistant Diabetes. J Sleep Med. 2020;17(1):44-48.

60. Chasens ER, Luyster FS. Effect of Sleep Disturbances on Quality of Life, Diabetes Self-Care Behavior, and Patient-Reported Outcomes. Diabetes Spectr. 2016;29(1):20-23.

\section{SUPPLEMENTARY DATA}

\section{Description of confounding factors included in univariate analyses}

After a review of the literature on cardiovascular risk factors in type 2 diabetics ${ }^{1-9}$, the potential confounding factors included in this study were antidiabetic therapy (categorised: lifestyle changes, untreated, oral medications, insulin therapy), diabetes status (categorised: controlled, uncontrolled), dyslipidaemia (categorised: absent, without statin therapy, with statin therapy), hypertension (categorised: absent, untreated, controlled, uncontrolled), depression (categorised: absent, remitted, current), sleep movement disorders (categorised: absent, moderate to severe PLMs, RLS alone or combined with moderate to severe PLMs), body mass index (categorised: $<25 \mathrm{~kg} / \mathrm{m}^{2}, \geq 25 \&<30 \mathrm{~kg} / \mathrm{m}^{2}, \geq 30 \mathrm{~kg} / \mathrm{m}^{2}$ ), age (categorised: $<55$ years, $\geq 55$ years), CRP levels (categorised: $<1 \mathrm{mg} / \mathrm{L}, \geq 1 \&<3 \mathrm{mg} / \mathrm{L}, \geq 3 \mathrm{mg} / \mathrm{L}$ ), ESS score (categorised: $\leq 10,>10)$ and as binary variables: gender, aspirin therapy, benzodiazepine receptor agonists, antidepressant therapy, alcohol consumption, smoking, caffeine consumption, cardiovascular comorbidities and snoring.

\section{REFERENCES}

1. McGurnaghan S, Blackbourn LAK, Mocevic E, Haagen Panton U, McCrimmon RJ, Sattar N, Wild S, Colhoun HM. Cardiovascular disease prevalence and risk factor prevalence in Type 2 diabetes: a contemporary analysis. Diabet Med. 2019;36(6):718-725.

2. Wang H, Ba Y, Cai RC, Xing Q. Association between diabetes mellitus and the risk for major cardiovascular outcomes and all-cause mortality in women compared with men: a meta-analysis of prospective cohort studies. BMJ Open. 2019;9(7):e024935.

3. Rubin RR, Peyrot M, Gaussoin SA, Espeland MA, Williamson D, Faulconbridge LF, Wadden TA, Ewing L, Safford M, Evans-Hudnall G, Wing RR, Knowler WC; Look AHEAD Research Group. Four-year analysis of cardiovascular disease risk factors, depression symptoms, and antidepressant medicine use in the Look AHEAD (Action for Health in Diabetes) clinical trial of weight loss in diabetes. Diabetes Care. 2013;36(5):1088-1094.

4. Hein M, Lanquart JP, Loas G, Hubain P, Linkowski P. Objective sleep alterations and long-term use of short or intermediate half-life benzodiazepine receptor agonists are risk factors for high blood pressure in individuals with insomnia: a study in 1272 individuals referred for sleep examinations. Sleep Med. 2019;53:115-123.

5. Zhang WL, Lopez-Garcia E, Li TY, Hu FB, van Dam RM. Coffee consumption and risk of cardiovascular events and all-cause mortality among women with type 2 diabetes. Diabetologia. 2009;52(5):810-817.

6. Bener A, Al-Hamaq AOAA, Ağan AF, Öztürk M, Ömer A. The prevalence of restless legs syndrome and comorbid condition among patient with type 2 diabetic mellitus visiting primary healthcare. J Family Med Prim Care. 2019;8(12):3814-3820.

7. Heldgaard PE, Henriksen JE, Sidelmann JJ, Olivarius Nde F, Siersma VD, Gram JB. Similar cardiovascular risk factor profile in screen-detected and known type 2 diabetic subjects. Scand J Prim Health Care. 2011;29(2):85-91.

8. Seidu S, Kunutsor SK, Sesso HD, Gaziano JM, Buring JE, Roncaglioni MC, Khunti K. Aspirin has potential benefits for primary prevention of cardiovascular outcomes in diabetes: updated literature-based and individual participant data meta-analyses of randomized controlled trials. Cardiovasc Diabetol. 2019;18(1):70.

9. Zhang Y, Pan XF, Chen J, Xia L, Cao A, Zhang Y, Wang J, Li H, Yang K, Guo K, He M, Pan A. Combined lifestyle factors and risk of incident type 2 diabetes and prognosis among individuals with type 2 diabetes: a systematic review and meta- analysis of prospective cohort studies. Diabetologia. 2020;63(1):21-33. 